\title{
Parvovirus B19 infection in sickle cell disease: An analysis from the Centers for Disease Control haemoglobinopathy blood surveillance project
}

\author{
Suvankar Majumdar ${ }^{1,2}$ (1) | Christopher J. Bean ${ }^{3}$ (]) | Christine De Staercke ${ }^{3}$ | \\ James Bost $^{1}$ | Robert Nickel ${ }^{1}$ | Thomas Coates ${ }^{4}$ | Andrew Campbell ${ }^{1,5}$ | \\ Alexis Thompson ${ }^{6}$
}

${ }^{1}$ Children's National Medical Center, George Washington University School of Medicine \& Health Sciences, Washington, DC

${ }^{2}$ Department of Pediatrics, University of Mississippi Medical Center, Jackson, Mississippi

${ }^{3}$ Division of Blood Disorders, National Center on Birth Defects and Developmental Disabilities, Centers for Disease Control and Prevention, Atlanta, Georgia

${ }^{4}$ Division of Hematology, Children's Hospital Los Angeles, Los Angeles, California

${ }^{5}$ Department of Pediatrics, University of Michigan, Ann Arbor, Michigan

${ }^{6}$ Feinberg School of Medicine, Northwestern University, Chicago, Illinois

\section{Correspondence}

Suvankar Majumdar, Division of Hematology, Center for Cancer \& Blood Disorders, Children's National Medical Center, George Washington University School of Medicine \& Health Sciences, 111 Michigan Avenue NW, Washington DC 20010.

Email: smajumdar@childrensnational.org

Funding information

National Center on Birth Defects and Developmental Disabilities, Grant/Award Number: U1U50DD000879; Centers for Disease Control and Prevention

\author{
Summary \\ Objective: In the multicentre Haemoglobinopathy Blood Surveillance Project, to eval- \\ uate the seroprevalence of parvovirus B19 and DNA viral load in sickle cell dis- \\ ease (SCD).
}

Background: Although the epidemiology of parvovirus B19 seropositivity in SCD has been well documented, there are few studies that have assessed possible persistent parvovirus DNAemia and associated risk factors including blood transfusion.

Methods: A qualitative analysis of parvovirus B19 serology using ELISA and quantitative parvovirus B19 DNA by RT-PCR was performed in patients with SCD.

Results: Of 322 patients, 113 (35\%) were parvovirus IgG positive and 119 (37\%) were IgM positive at enrolment. The prevalence of IgG positivity increased with age. $71 / 322$ (22\%) were parvovirus DNA positive at enrolment with a mean viral load of $15227 \pm 55227$ SD. (range 72-329 $238 \mathrm{IU} / \mathrm{mL}$ ). Patients who were positive for parvovirus B19 DNA received a significantly higher red blood cell transfusion volume in the prior year compared to patients who were negative (mean RBC volume $=8310 \mathrm{~mL}$ vs $5435 \mathrm{~mL}$, respectively; $P=.0073$ ). Seventy-seven patients had follow-up testing approximately 1 year after enrolment and 11/28 (39\%) patients had persistently positive IgM.

Conclusion: Further studies are needed to better understand the natural history of parvovirus B19 infection in SCD especially in relation to RBC transfusion as a risk factor, as well as disease outcome and severity.

\section{KEYWORDS}

hemoglobinopathy, parvovirus B19, sickle

\section{1 | BACKGROUND}

Sickle cell disease (SCD) is an autosomal recessive red blood cell disorder that occurs from a single base mutation in the beta globin gene, which leads to the production of abnormal haemoglobin (haemoglobin S) and sickling of red blood cells. The homozygous form of the disorder, haemoglobin SS, and other compound heterozygotes such as haemoglobin SC, haemoglobin S $\beta$ thalassemia, of different genotypes are collectively known as SCD. Human parvovirus B19 infection is a common childhood infection that may be associated with lifethreatening anaemia from transient aplastic crisis (TAC) in individuals with SCD. The virus is trophic for erythroid precursors in the bone 
marrow and is able to shut down red blood production, thus accentuating the severity of anaemia. In the United States, there is a high ( $\approx 30 \%-50 \%$ ) serologic prevalence of previous parvovirus B19 infection in children with SCD, with seroconversion rates that increase with age. ${ }^{1-3}$ However, interestingly, Zimmerman et al. found that only $27 \%$ of patients with sickle cell anaemia and who were seropositive for parvovirus B19 had a clinically recognised TAC, suggesting that many acquire parvovirus without developing severe symptoms of TAC. $^{3}$ In a cross-sectional study, Makhlouf et al showed that parvovirus B19 DNAemia appears to be common in SCD. Among 64 haemoglobin SS (sickle cell anaemia) and 36 haemoglobin AS (sickle cell trait) children with IgG positive titers, 24 had evidence of parvovirus B19 DNA as detected by polymerase chain reaction (PCR). ${ }^{4}$ Patients with viremia were reported to have a lower baseline haemoglobin than those with a previous history of parvovirus B19 infection denoted by serological markers but no active viremia. ${ }^{4}$

Although the epidemiology of parvovirus B19 seropositivity in SCD has been well documented, there are few studies that have assessed the presence of persistent DNAemia and if there is an association to RBC transfusion. ${ }^{1-6}$ Persistent parvovirus B19 DNAemia has been described mainly in immunocompromised hosts with leukaemia and bone marrow/organ transplantation..$^{7-9}$ Further, tntravenous immunoglobulin has been reported to eradicate the virus in immunocompromised hosts. ${ }^{10,11}$ Hydroxyurea is a commonly prescribed medication for SCD that increases haemoglobin F production and thereby decreases red blood cell haemolysis, but it also has significant effects on many immune cell counts. ${ }^{12}$ Although hydroxyurea has been shown to attenuate the severity of TAC without affecting the durable serologic response to parvovirus B19, ${ }^{1}$ it is unknown if hydroxyurea therapy is associated with a decrease of parvovirus B19 DNAemia in patients with SCD.

The overall goal of the Centers for Disease Control (CDC) multicentre study on Blood Safety Surveillance among People with Blood Disorders was to obtain a better understanding of blood transfusion related complications in haemoglobin disorders, for example, rates of allo-immunisation, allergic reactions, burden of emerging pathogens etc. Using stored plasma samples, the primary objective of this study was to evaluate the seroprevalence of parvovirus B19 and the DNA viral load in individuals with SCD, and to assess for potential risk factors such as transfusion and hydroxyurea for persistent parvovirus B19 DNAemia in this high-risk population.

\section{2 | METHODS}

A total of 322 paediatric patients diagnosed with SCD were enrolled in this study. Plasma was obtained at enrolment, and if available, approximately 1 year later. Plasma samples were stored at $-80^{\circ} \mathrm{C}$ until antibody testing and viral DNA extraction. Demographic information, diagnosis, red blood cell transfusion history in the past year (number and volume of packed red blood cell), hydroxyurea use, and history of splenectomy were collected at enrolment. The qualitative analysis of human parvovirus B19 antibody IgG and human parvovirus B19 antibody $\lg M$ of study plasma samples was conducted at the CDC using MyBioSource Human parvovirus B19 IgG and IgM ELISA kit (Solid phase enzyme-linked immunosorbent assay; Cat\# MBS9304327 and MBS9301249). Plasma samples were diluted 5 -fold and assayed in duplicates. Positive and negative control samples were used to determine the cut off values. Purified Viral parvovirus B19 DNA was extracted from the same plasma sample aliquots using the ZR Viral DNA Kit (The Epigenetics Company-ZYMO RESEARCH Corp [Cat\# D3016]). Denaturation of viral DNA and recovery of DNA was accomplished using the unique ZR Viral DNA Buffer and individual Zymo-Spin IC columns. DNA was eluted with $15 \mu \mathrm{L}$ of elution buffer (DNA recovery up to $1.2-2.3 \mu \mathrm{g}$ total DNA) and assayed in downstream RT-PCR application with the RealStar Parvovirus B19 PCR Kit 1.0 from Altona Diagnostics (Hamburg, Germany). ${ }^{13}$ The quantification standards contained standardised concentrations of parvovirus B19-specific DNA. These quantification standards were calibrated against the second WHO International Standard for Parvovirus B19 for Nucleic Acid Amplification Techniques (NIBSC code: 99/802) and used to generate a Standard Curve $(10000-0.625 \mathrm{IU} / \mu \mathrm{L}) .{ }^{14}$ Viral loads in study samples were calculated as the product of eluate volume $(15 \mu \mathrm{L})$ and eluate viral load divided by the volume of sample input $(0.2 \mathrm{~mL})$ and were reported in $\mathrm{IU} / \mathrm{mL}$. The limit of detection (LOD) corresponds to $68 \mathrm{IU} / \mathrm{mL}$ and was defined as the LOD in the tested eluate of parvovirus B19-specific DNA that can be detected: $0.41 \mathrm{IU} / \mu \mathrm{L}$ [95\% confidence interval $(\mathrm{Cl}): 0.27-0.90 \mathrm{IU} / \mu \mathrm{L}$ ]. A conservative cutoff value greater than $0.90 \mathrm{IU} / \mu \mathrm{L}$ in the eluate was used as the threshold for positivity.

\subsection{Statistical methods}

Descriptive statistics were provided as mean and SD and/or as median and the IQR (interquartile range). Comparisons of two categorical variables were done using chi-squared test. Comparing of continuous outcomes to categorical predictors were done using $t$ tests if the samples were large enough (transformations were done to verify significance remained at 0.05 if data were skewed). The Wilcoxon signed-rank test was used to assess the relationship between parvovirus IgG positivity and RBC transfusions.

\section{3 | RESULTS}

A total of 322 participants had SCD and parvovirus B19 testing with the following genotypes: haemoglobin SS ( $n=291)$, haemoglobin SC ( $n=15)$, haemoglobin $S / \beta^{0}$ thalassemia $(n=9)$, haemoglobin $S \beta+$ thalassemia ( $n=6$ ), and other compound heterozygous form of SCD $(n=1)$. The F:M ratio was 0.9:1 with a mean age of 14.1 years $\pm 9.6 \mathrm{SD}$ (range $1-58$ years). $113(\approx 35 \%)$ had a history of hydroxyurea use and $25(\approx 8 \%)$ had a history of splenectomy. All participants were tested and found to be negative for HIV.

At enrolment, 113/322 (35\%) were IgG positive. 144/322 (45\%) patients had never been infected with parvovirus B19 infection 
TABLE 1 Parvovirus B19 IgM, IgG and DNA viral load in 322 patients with sickle cell disease at enrolment

\begin{tabular}{|c|c|c|c|c|c|}
\hline Interpretation & $\lg M$ & $\operatorname{lgG}$ & PCR & Viral load; mean (SD) IU/mL; median (IQR) IU $/ \mathrm{mL}$ & $\mathbf{N}$ \\
\hline \multirow[t]{2}{*}{ Never infected } & \multirow[t]{2}{*}{ Neg } & \multirow[t]{2}{*}{ Neg } & \multirow[t]{2}{*}{$\mathrm{Neg}$} & $3.1(11.3)$ & \multirow[t]{2}{*}{144} \\
\hline & & & & $0(0-0)$ & \\
\hline Old infection, cleared & Neg & Pos & Neg & $0(0-31.0)$ & 29 \\
\hline Recent infection, cleared & Pos & Pos & $\mathrm{Neg}$ & $10.5(18.8)$ & 54 \\
\hline \multirow[t]{2}{*}{ Recent infection, cleared } & \multirow[t]{2}{*}{ Pos } & \multirow[t]{2}{*}{$\mathrm{Neg}$} & \multirow[t]{2}{*}{ Neg } & $9.1(17.8)$ & \multirow[t]{2}{*}{24} \\
\hline & & & & $0(0-4.0)$ & \\
\hline \multirow[t]{2}{*}{ Early recent infection, active } & \multirow[t]{2}{*}{ Neg } & \multirow[t]{2}{*}{ Neg } & \multirow[t]{2}{*}{ Pos } & 17054.3 (71 632.0) & \multirow[t]{2}{*}{21} \\
\hline & & & & $162.1(95.95 .3-685.4)$ & \\
\hline Recent infection, active & Pos & Pos & Pos & $7595.2(25672.3)$ & 21 \\
\hline \multirow[t]{2}{*}{ Chronic infection } & \multirow[t]{2}{*}{ Neg } & \multirow[t]{2}{*}{ Pos } & Pos & 12037.4 (32 004.2) & 9 \\
\hline & & & & $588.8(199.4-1396.6)$ & \\
\hline
\end{tabular}

Note: The cutoff for PCR positivity was $>0.90 \mathrm{IU} / \mu \mathrm{L}$ in the tested eluate or a viral load in the original sample of $>68.00 \mathrm{IU} / \mathrm{mL}$.

(Table 1). Overall, the IgG seroprevalence increased with age: $28 \%$ (0-5 years), $\quad 32 \% \quad(>5-10$ years), $\quad 35 \% \quad(>10-15$ years $), \quad 30 \%$ (>15-20 years), and $48 \%$ (>20 years).

There were 119/322 (37\%) SCD patients who were IgM positive. Of those IgM positive, 41 (34\%) had quantifiable parvovirus B19 DNA indicative of recent active infection. In the enrolment samples, $22 \%$ (71/322) of patients had a positive parvovirus PCR regardless of their enrolment serology status, with a mean viral load $15227 \pm 55227$ SD. (range 72-329 $238 \mathrm{lU} / \mathrm{mL}$ ). There was no significant difference in parvovirus B19 DNA viral load with respect to hydroxyurea use $(P=.999)$, history of splenectomy $(P=.999)$, or age $(P=.162) .58 / 322$ $(18 \%)$ had no history of red blood cell transfusion in the prior year. Of 264 subjects who received a red blood cell transfusion, the mean \pm SD volume transfused in the prior year was $6338 \pm 7060 \mathrm{~mL}$. There was a significant difference in DNA viral load between individuals who received a RBC transfusion vs those who did not receive a transfusion (mean viral load $4214 \mathrm{IU} / \mathrm{mL}$ vs $188 \mathrm{IU} / \mathrm{mL}$ respectively; $P=.034)$.

A total of $86 / 322$ (27\%) participants had a history of stroke as an indication for chronic RBC transfusion, and 39 subjects had received at least one erythrocytopharesis (red blood cell exchange transfusion) in the prior year. Patients who were positive for parvovirus B19 DNA received a significantly higher red blood cell transfusion volume in the prior year compared to patients who were negative (mean RBC volume $=8310 \mathrm{~mL}$ vs $5435 \mathrm{~mL}$ respectively; $P=.0073$ ).

Seventy-seven patients had a second sample collected approximately 1 year after the first sample (Table 2). In this cohort, 2/14 subjects that were initially PCR positive had remained DNAemic in the second year of testing, with a mean viral load at enrolment and follow up of $169 \mathrm{IU} / \mathrm{mL}$ and $139 \mathrm{IU} / \mathrm{mL}$, respectively. Antibody status for
TAB LE 2 Demographic and parvovirus serology in 77 subjects who had repeat testing 1 year later

\begin{tabular}{|ll|}
\hline Genotype & Number (\%) \\
\hline Haemoglobin SS & 74 \\
Haemoglobin SC & 1 \\
Haemoglobin S $\beta$ thalassemia & 1 \\
\hline Haemoglobin S $\beta$ + thalassemia & 1 \\
\hline Age (mean \pm SD) & $13.2 \pm 6.9$ years \\
\hline Gender (female) & $34(44 \%)$ \\
\hline Proportion that stayed IgG positive & $14 / 21(67 \%)$ \\
\hline Proportion that stayed IgM positive & $11 / 28(39 \%)$ \\
\hline Proportion that stayed PCR positive & $2 / 14(14 \%)$ \\
\hline
\end{tabular}

these 14 subjects showed 3/14 were IgG positive and 8/14 were IgM positive at enrolment. As noted in Tables 1, 21/322 (6.5\%) were parvovirus B19 DNA positive but negative for IgM and IgG at enrolment. Of those 21 subjects, five had follow-up testing of which four became parvovirus B19 DNA negative and one continued to be positive. $11 / 28$ (39\%) patients with a positive IgM at enrolment had persistently positive IgM on repeat testing with $7 / 11$ of these patients being parvovirus PCR negative at both time points and 4/11 of these patients changing from PCR positive to negative suggesting that positive IgM titers may continue for at least 1 year from infection (Table 2). 14/21 who were IgG positive at enrolment remained parvovirus IgG positive and there was no association with history of RBC transfusion in the past year $(P=.5001)$. 


\section{4 | DISCUSSION}

Our study shows that the presence of parvovirus B19 DNAemia in SCD is related to red blood cell transfusion history. Patients with parvovirus B19 DNAemia may have received more RBC transfusions because of their parvovirus infection causing anaemia. Alternatively, it is possible that RBC transfusions may transmit parvovirus B19 DNA. A study in blood donors showed that positive detection of parvovirus B19 DNA approximately 6 months after acute infection can be due to the presence of remnant DNA strands and not infectious virions. ${ }^{15}$ Furthermore, the potential transmission of parvovirus via blood products has been previously reported. In a study of 75 parvovirus, B19 infected blood donors, DNA persisted for a mean of 21.5 months. ${ }^{16}$ Significantly, parvovirus B19 transmission by cellular blood products has been found to correlate with viral concentration. In a study from Germany, parvovirus DNA was detected in 9 of 19 recipients of red blood cells from donors who had a viral load of greater than $10^{5} \mathrm{lU} / \mathrm{mL}$, whereas none of the of 16 recipients of RBCs from those with less than $10^{5} \mathrm{IU} / \mathrm{mL}$ were positive for parvovirus B19 DNA. ${ }^{16}$ In a linked donor -recipient study to evaluate parvovirus B19 transmission by blood component transfusion, no transmission to 24 susceptible recipients from transfusion of components with B19 DNA at concentrations less than $10^{6} \mathrm{IU} / \mathrm{mL}$ (upper $95 \%$ confidence interval, 11.7\%) was found. ${ }^{17}$ Also, of 105 DNA-positive donations and 112 positive components transfused to 107 distinct recipients, no clinical disease related to parvovirus B19 was observed, although it is difficult to draw the same predication of a benign clinical course in patients with SCD who are known to be high risk of a more severe clinical course because of their underlying haemolytic anaemia.

Indications for red blood cell transfusions in SCD include history of acute stroke for which patients are often placed on lifelong monthly RBC transfusions to prevent stroke recurrence (secondary prophylaxis). Some patients may receive long-term erythrocytopharesis, which involves exposure to large amounts of red blood cells. Other indications for intermittent red blood cell transfusion are related to disease severity such as acute chest syndrome (a common lung complication in SCD) and severe anaemia from acute parvovirus B19 infection or hyperhaemolysis. Parvovirus B19V DNA is detectable in $0.5 \%$ to $0.9 \%$ of blood donations, with most showing relatively low DNA concentrations $(<100-1000 \mathrm{IU} / \mathrm{mL})$. Furthermore, it is unclear from our results if transfusions caused the observed increased DNAemia, or if this DNAemia resulted in any clinical consequences. We found that only a small proportion of individuals with SCD (<3\%) have remained parvovirus DNAemic with relatively low levels of DNA. Persistent parvovirus DNA has been reported in immunocompromised hosts. However, our cohort of 322 subjects were tested and found not to be immuosuppressed from HIV infection although other medical conditions associated with immune suppression could not be excluded. Overall, our results suggest that a cautious approach would be to perform blood donor screening for parvovirus B19 with an appropriately set cutoff infectivity for "parvovirus safe" red blood cells in this high-risk population receiving blood transfusion. In addition, continued efforts should be placed on the development of candidate vaccines against parvovirus B19, especially due to the risk of increased morbidity in SCD. ${ }^{18}$ The risk to this approach may be to further complicate finding extended antigenmatched RBCs for SCD patients to prevent alloimmunization, which is supported as standard of care. ${ }^{19}$

Importantly, we did not find an association with parvovirus DNA viral load and hydroxyurea use despite its known effects on the immune system and risk of neutropenia. This finding is consistent with the results from controlled clinical trials in SCD, which have found that hydroxyruea does not increase the general risk of infection. ${ }^{20,21}$

Previous reports in the general population have shown that parvovirus may persist but the implications in SCD of continued parvovirus DNAemia are unknown. Notably, in the general population, recent parvovirus infection-with B19 DNA detected by PCR, and IgG and IgM positivity-as well as persistent infection with undetectable IgM, have been linked to pro-inflammatory cytokines and chronic arthritis/ arthropathy ${ }^{8,22,23}$; and it is unknown if this contributes towards the process of vaso-occlusion in SCD leading to organ damage. Interestingly, a history of parvovirus B19 infection has been shown to be associated with silent cerebral infarcts in SCD. In a retrospective cross-sectional cohort study design in 958 sickle cell participants who underwent brain magnetic resonance imaging, silent cerebral infarct was present in $30 \%$ of participants and $17 \%$ had a history of a parvovirus B19 infection. ${ }^{24}$

Our findings of increasing seroprevalence rates of Ig $G$ positivity with age are consistent with other previously reported studies in the United States. ${ }^{1-3}$ The serology and PCR results suggest that many patients across all age groups have never been infected with parvovirus B19, although interpretation may be difficult as some patients may lose their Ig G positivity over time. Also, the 21 subjects who were parvovirus B19 PCR positive but Ig M/Ig G negative suggests early recent infection or possibly the acquisition of parvovirus via blood transfusion. While IgM titers typically peak at 3 to 4 weeks from onset of infection, our study shows that the IgM titers may remain positive over a longer period of time in SCD. Although this could indicate re-infection or viral persistence, durability of positive IgM titers over a long period of time has been reported in other conditions. $^{25}$

A limitation to our study is that no information was collected on a prior clinical TAC event or the timing of the most recent transfusion in relation to sample collection and thus only one total year of blood transfusion volume was assessed. In addition, information on complete blood counts was not obtained which would determine if the presence of persistent parvovirus B19 DNAemia affects the degree or severity of anaemia in SCD. Nonetheless, based on appropriate cuff off for infectivity, "parvovirus safe" red cells could be supplied to this high-risk population receiving blood transfusion as a measure of safety. Further studies are needed to better understand the natural history of parvovirus B19 infection in SCD especially in relation to RBC transfusion and any association with disease outcome and severity.

\section{ACKNOWLEDGMENTS}

We would like to acknowledge the patients and families who participated in this project (Blood Safety Surveillance Among Persons with 
Sickle Cell Disease; National Center for Birth Defects and Developmental Disabilities, Centers for Disease Control and Prevention, U1U50DD000879). S.M. wrote the manuscript. R.N. critically edited the manuscript. C.J.B. and C.D.S. performed the parvovirus testing at the CDC. J.B. performed the statistical analysis. A.T., A.C., and T.C. were site PIs and critically reviewed the manuscript.

\section{CONFLICT OF INTEREST}

The findings and conclusions in this report are those of the authors and do not necessarily represent the official position of the Centers for Disease Control and Prevention.

\section{ORCID}

Suvankar Majumdar (D) https://orcid.org/0000-0003-1471-738X Christopher J. Bean (D) https://orcid.org/0000-0001-7433-9769

\section{REFERENCES}

1. Hankins JS, Penkert RR, Lavoie P, Tang L, Sun Y, Hurwitz JL. Parvovirus $\mathrm{B} 19$ infection in children with sickle cell disease in the hydroxyurea era. Exp Biol Med (Maywood). 2016;241(7):749-754.

2. Smith-Whitley $\mathrm{K}$, Zhao H, Hodinka RL, et al. Epidemiology of human parvovirus B19 in children with sickle cell disease. Blood. 2004;103(2): 422-427.

3. Zimmerman SA, Davis JS, Schultz WH, Ware RE. Subclinical parvovirus $B 19$ infection in children with sickle cell anemia. J Pediatr Hematol Oncol. 2003;25(5):387-389.

4. Makhlouf MM, Elwakil SG, Ibrahim NS. Molecular and serological assessment of parvovirus B-19 infection in Egyptian children with sickle cell disease. J Microbiol Immunol Infect. 2017;50(5):565-569. https://doi.org/10.1016/j.jmii.2015.10.016.

5. Slavov SN, Kashima S, Pinto AC, Covas DT. Human parvovirus B19: general considerations and impact on patients with sickle-cell disease and thalassemia and on blood transfusions. FEMS Immunol Med Microbiol. 2011;62(3):247-262.

6. Slavov SN, Haddad SK, Silva-Pinto AC, et al. Molecular and phylogenetic analyses of human parvovirus B19 isolated from Brazilian patients with sickle cell disease and beta-thalassemia major and healthy blood donors. J Med Virol. 2012;84(10):1652-1665.

7. Cohen BJ, Beard S, Knowles WA, et al. Chronic anemia due to parvovirus $B 19$ infection in a bone marrow transplant patient after platelet transfusion. Transfusion. 1997;37(9):947-952.

8. Heegaard ED, Brown KE. Human parvovirus B19. Clin Microbiol Rev. 2002;15(3):485-505

9. Lindblom A, Heyman M, Gustafsson I, et al. Parvovirus B19 infection in children with acute lymphoblastic leukemia is associated with cytopenia resulting in prolonged interruptions of chemotherapy. Clin Infect Dis. 2008;46(4):528-536.

10. Crabol Y, Terrier B, Rozenberg F, et al. Intravenous immunoglobulin therapy for pure red cell aplasia related to human parvovirus b19 infection: a retrospective study of 10 patients and review of the literature. Clin Infect Dis. 2013;56(7):968-977.

11. Liefeldt L, Buhl M, Schweickert B, et al. Eradication of parvovirus B19 infection after renal transplantation requires reduction of immunosuppression and high-dose immunoglobulin therapy. Nephrol Dial Transplant. 2002;17(10):1840-1842.
12. Nickel RS, Osunkwo I, Garrett A, et al. Immune parameter analysis of children with sickle cell disease on hydroxycarbamide or chronic transfusion therapy. Br J Haematol. 2015;169(4):574-583.

13. Kern C KT. RealStar ${ }^{\circledR}$ Parvovirus B19 PCR Kit 1.0 from Altona Diagnostics. Hamburg, Germany; 2017. https://www.altona-diagnostics.com/ files/public/Content\%20Homepage/-\%2002\%20RealStar/MAN\%20\%20CE\%20-\%20EN/RealStar\%20Parvovirus\%20B19\%20PCR\%20Kit \%201.0_WEB_CE_EN-S03.pdf.

14. James C, Karen C, Funke G, Jorgensen JH, Landry ML, Warnock DW. Manual of Clinical Microbiology. 10th ed. Washington, DC: ASM Press; 2015.

15. Molenaar-de Backer MW, Russcher A, Kroes AC, Koppelman MH, Lanfermeijer M, Zaaijer HL. Detection of parvovirus B19 DNA in blood: viruses or DNA remnants? J Clin Virol. 2016;84:19-23.

16. Juhl D, Gorg S, Hennig H. Persistence of parvovirus B19 (B19V) DNA and humoral immune response in B19V-infected blood donors. Vox Sang. 2014;107(3):226-232.

17. Kleinman SH, Glynn SA, Lee TH, et al. Prevalence and quantitation of parvovirus B19 DNA levels in blood donors with a sensitive polymerase chain reaction screening assay. Transfusion. 2007;47(10):1756-1764.

18. Ballou WR, Reed JL, Noble W, Young NS, Koenig S. Safety and immunogenicity of a recombinant parvovirus B19 vaccine formulated with MF59C.1. J Infect Dis. 2003;187(4):675-678.

19. Buchanan G, Yawn B, Afenyi-Annan A, Ballas S, Hassell K, James A, Jordan L, Lanzkron S, Lottenberg R, Savage W, Tanabe P, Ware R, Murad MH. Evidence-Based Management of Sickle Cell Disease: Expert Panel Report. Washington, DC: National Institute of Health (NIH)/National Heart Lung Blood Institute (NHLBI). 2014.

20. Opoka RO, Ndugwa CM, Latham TS, et al. Novel use of Hydroxyurea in an African region with malaria (NOHARM): a trial for children with sickle cell anemia. Blood. 2017;130(24):2585-2593.

21. Tshilolo L, Tomlinson G, Williams TN, et al. Hydroxyurea for children with sickle cell Anemia in sub-Saharan Africa. N Engl J Med. 2019;380 (2):121-131.

22. Cassinotti P, Bas S, Siegl G, Vischer TL. Association between human parvovirus B19 infection and arthritis. Ann Rheum Dis. 1995;54(6): 498-500.

23. Reid DM, Reid TM, Brown T, Rennie JA, Eastmond CJ. Human parvovirus-associated arthritis: a clinical and laboratory description. Lancet. 1985;1(8426):422-425.

24. Ogunsile FJ, Currie KL, Rodeghier $M$, Kassim A, DeBaun MR, Sharma D. History of parvovirus B19 infection is associated with silent cerebral infarcts. Pediatr Blood Cancer. 2018;65(1). https://doi. org/10.1002/pbc.26767.

25. Murray KO, Garcia MN, Yan C, Gorchakov R. Persistence of detectable immunoglobulin $M$ antibodies up to 8 years after infection with West Nile virus. Am J Trop Med Hyg. 2013;89(5):996-1000.

How to cite this article: Majumdar S, Bean CJ, De Staercke C, et al. Parvovirus B19 infection in sickle cell disease: An analysis from the Centers for Disease Control haemoglobinopathy blood surveillance project. Transfusion Med. 2020;30:226-230. https://doi.org/10.1111/tme.12671 